\title{
Continuous Force Measurement in Limb Lengthening
}

\author{
Tariq Rahman', Robert E. Akins ${ }^{1}$, Jinyong Wee ${ }^{2}$ and William G. Mackenzie ${ }^{1}$
}

${ }^{1}$ Nemours/Alfred I. duPont Hospital for Children, 1600 Rockland Road, Wilmington, DE 19803, USA

${ }^{2}$ School of Biomedical Engineering, Drexel University, Philadelphia, PA 19104, USA

\begin{abstract}
Complications of limb lengthening include stress on soft tissue, premature consolidation, and bone non-union. This study reports on the development and testing of instrumentation that continually measures distraction forces in rabbits with the aim of relating the forces developed to bone growth and muscle physiology. A full bridge strain gage resistor set mounted to a unilateral distractor measured distraction force and stored the data on a self-contained logger attached to a jacket worn by the rabbit. Two rabbits underwent limb lengthening on one hind leg. Lengthening was set at $0.5 \mathrm{~mm} /$ day, twice per day for a total of $12 \mathrm{~mm}$. Tibialis anterior muscle and proximal and distal tibial growth plates from the operated and control legs were harvested after euthanasia for histomorphometric analysis. Radiographs were taken periodically throughout lengthening. Force data show characteristic overall increase in force. Force steadily decays after each lengthening. Peak forces appear to correlate with time between lengthenings. Histologic data show that the operated leg had an increased preponderance of type I muscle fibers, a decrease in type-I and type-II muscle fiber diameters, and a decrease in endogenous bone growth at the distal growth plate. Histomorphometric analysis showed that the lengthening paradigm employed altered distal bone growth and muscle fiber physiology during lengthening.
\end{abstract}

Keywords: Distraction force; Distractor; Limb lengthening.

\section{Introduction}

Limb lengthening is a common procedure used to correct limb length discrepancy. The bone is cut and mechanically separated by gradually pulling apart the two segments. New bone is generated in the distraction gap by callus formation, which eventually mineralizes to bone. The standard rate of lengthening used in the clinic is $1 \mathrm{~mm} /$ day. There may be complications associated with the procedure including joint contractures, angular deformities, and articular cartilage injury [1]. Lengthening may result in tightness of the musculotendinous units, fasciae, and neurovascular structures. The response of the soft tissues to distraction forces has been provisionally studied [2-4]. However, the histo-pathomorphological changes and proliferative reaction have not been defined, and the factors affecting the ability of the soft tissue to accommodate the limb lengthening are not clear.

Forces during lengthening have been evaluated in both animals and humans. Maximum loads of $95 \mathrm{~N}$ have been found when the rabbit tibia was lengthened $10 \%$ with a uniplanar bilateral external fixator [5]. Forces measured during $15 \%$ lengthening of dog tibiae ranged from $110 \mathrm{~N}$ to $155 \mathrm{~N}[6]$. Tibial $[7,8]$ and femoral [9-11] forces have been measured in humans. Although these studies used different techniques of force measurement, the results have been relatively consistent in magnitude.

Paley et al. [12] stated that lengthening of the limb by $10 \%$ of the original bone length rarely causes soft tissue contracture. However, Kawamura et al. [13] have shown that biochemical abnormalities can occur under experimental conditions in normal muscle when there is a $10 \%$ acute increase in limb length. They have found that the aldolase and creatine-phosphokinase rose to between 5 to 10 times their normal values after rapid, one-stage $10 \%$ lengthening. Holly et al. [14] concluded that muscle grows and adapts enzymatically when stretched; however, the response in twitch and tonic muscle is dissimilar.

Shen and Aronson [15] demonstrated acute stiffness of the adult rat gastrocnemius muscle after tibial lengthening up to $20 \%$. This was attributed to an increase in endomysial and perimysial fibrosis. Lee et al. [16] examined the histopathological changes in the adult rabbit gastrocnemius after tibia lengthening. They found a significant increase in muscle nuclei internalization and endomyseal fibrosis after a $20 \%$ tibia lengthening. Fiber size variation was mainly due to an increase in the proportion of the atrophied muscle fibers instead of hypertrophied fibers, which were found only occasionally. In Simpson et al. [17] study, active muscle function showed adaptation as long as the rate of lengthening was $1.0 \mathrm{~mm} /$ day or less in an adult rabbit model; however, the muscle compliance was only normal with a lengthening rate of $0.4 \mathrm{~mm} /$ day. Degenerative changes of the muscle fibers were found even at rates of less than $1.0 \mathrm{~mm} /$ day, and the abnormalities, such as fibrous tissue proliferation, increased with increasing rate of lengthening $[18,19]$. It appears that the ideal (ie, tissue preservation) rate of lengthening varies for different tissues. This study measures the forces developed in lengthening and how they correlate to growth plate and soft tissue information after euthanasia.

\section{Materials and Methods}

\section{Distractor design}

The distractor comprises two basic sections (Figure 1). The box structure in the middle is a parallel beam load cell with a full bridge strain gage transducer. Pressed into each end of the load cell is a threaded rod on which slides a car whose position is set by the encased thumbwheel. The fixation pins are attached to the car. As the thumbwheel turns, one segment of the bone moves away from the other.

*Corresponding author: Tariq Rahman, PhD, Nemours Biomedical Research, Nemours/Alfred I. duPont Hospital for Children, P.O. Box 269, Wilmington, DE 19899, USA, Tel: 302-651-6831; Fax: 302-651-6782, E-mail: trahman@nemours. org

Received November 21, 2011; Accepted December 07, 2011; Published December 08, 2011

Citation: Rahman T, Akins RE, Wee J, Mackenzie WG (2011) Continuous Force Measurement in Limb Lengthening. J Bioengineer \& Biomedical Sci 1:104 doi:10.4172/2155-9538.1000104

Copyright: @ 2011 Rahman T, et al. This is an open-access article distributed under the terms of the Creative Commons Attribution License, which permits unrestricted use, distribution, and reproduction in any medium, provided the original author and source are credited. 

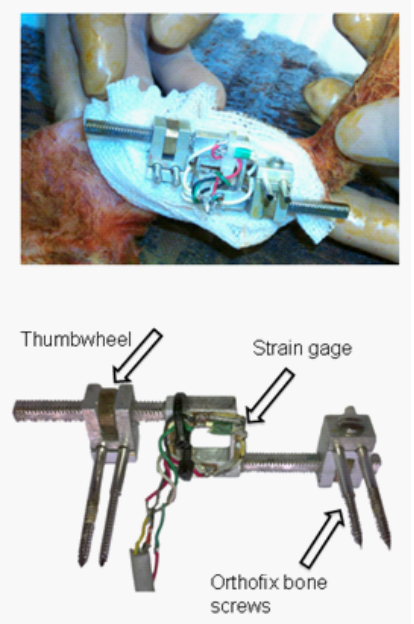

Figure 1: Unilateral fixator designed for the rabbit study. The upper image shows the fixator mounted on the rabbit tibia immediately after surgery. The lower image shows the main components of the distractor with full bridge strain gages on the two legs of the device.

The design of the load cell was chosen for several reasons. First, it is both compact and lightweight. The overall dimensions were minimized while still allowing space for the strain gauges and the thumbwheel. Second, the structure mechanically isolates the strain gauges so that only axial distraction forces are measured.

The design of the distraction mechanism was also dominated by space considerations. The threaded rod is $40 \mathrm{~mm}$ long with flats on all four sides and a pitch of $1 \mathrm{~mm}$ per revolution. The car is U-shaped to capture the thumbwheel and has square holes on each ledge of the $\mathrm{U}$, which allows it to slide along the screw without rotation. By turning the thumbwheel one revolution, the car advances $1 \mathrm{~mm}$ along the screw. The car also has grooves into which 2-mm diameter fixation pins can be captured. A mating cap clamps the screws to the car.

The signal from the strain gages (Micro-Measurements, Raleigh, NC) went to an electronic box that was carried in a jacket that the rabbit wore for the duration of the distraction. The box contained the signal conditioning and amplification circuitry, as well as a data logger (Onset Computer, Bourne, MA). The distraction force was set to record every two minutes. The data were uploaded to a PC periodically (once/week on average) and examined for reliability. The distractor was calibrated by suspending a known weight at one end.

\section{Lengthening procedure}

The study was approved by the Institutional Animal Care and Use Committee and was conducted in accordance with the Guidelines for the Care and Use of Laboratory Animals as set forth by the National Institutes of Health and the US Department of Agriculture. The rabbits were anesthetized with $1 \mathrm{mg} / \mathrm{kg}$ acepromazine and $25 \mathrm{mg} / \mathrm{kg}$ ketamine. Two 2.5-mm tapered threaded screws (Orthofix, Lewisville, TX) were inserted into the left proximal and distal tibiae between the physes. After attaching the distraction device to the Orthofix screws, a transverse subperiosteal fracture along the drilled holes was manually made at the level of the mid-diaphysis. Antibiotics were administered prophylactically, and postoperative analgesics were used. Five days after the operation, twice-daily distraction was initiated. Radiographs were taken once a week throughout lengthening.

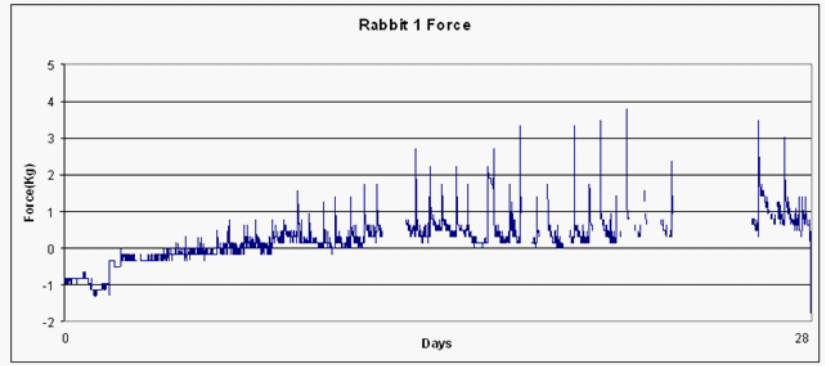

Figure 2: Force generated in the distraction zone for rabbit 1 undergoing lengthening. The peaks indicate the force right after lengthening. The gaps in the data indicate the few times that the rabbit chewed through the wires.

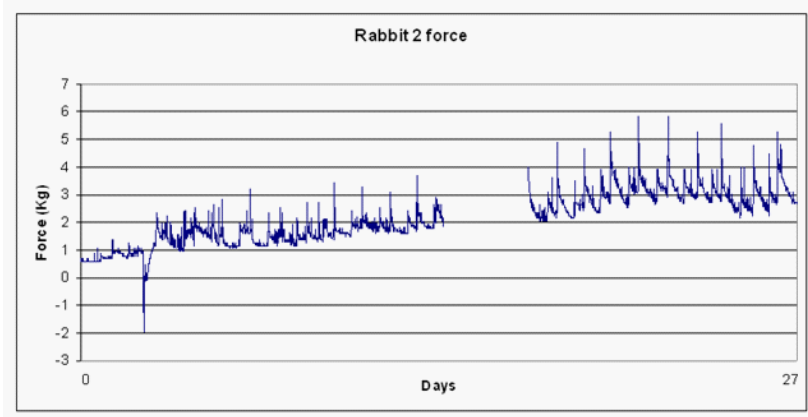

Figure 3: Force generated in the distraction zone for rabbit 2 undergoing lengthening. The missing data are due to chewing of the load cell wires.

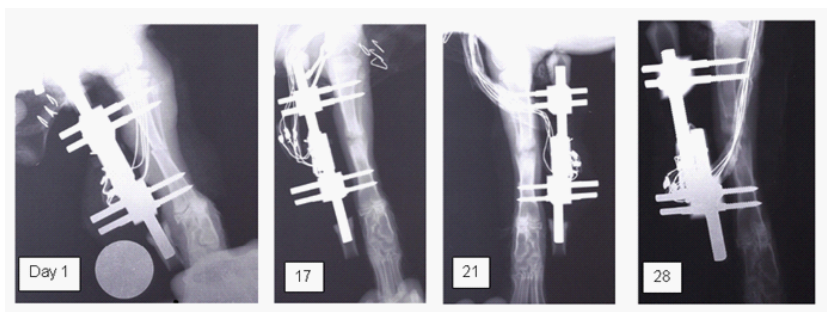

Figure 4: Radiographs of rabbit 1 taken on day 1 after surgery, day 17, day 21 , and day 28.

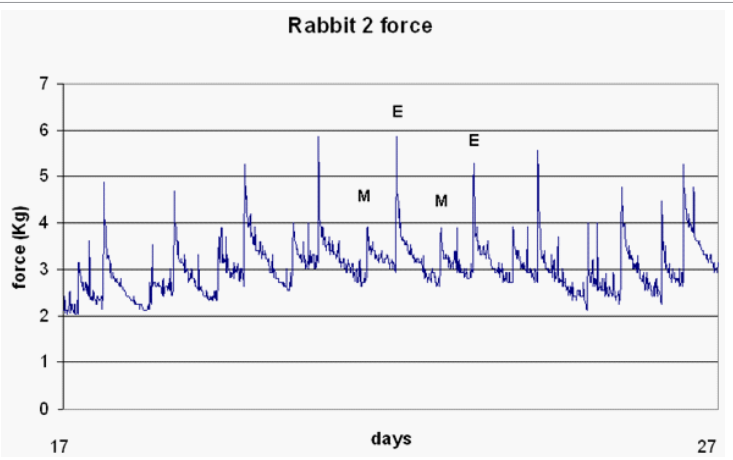

Figure 5: Force data from day 17 to day 27 for rabbit 2. This illustrates a pattern of peaks followed by muscle adaptation in response to the lengthening. $E$ indicates the evening lengthening and $M$ indicates the morning lengthening

\section{Muscle histology}

Since muscle fibers can respond to chronic stretch and increased 
tone by altering the distribution of slow, oxidative, fatigue-resistant (type I) versus fast, glycolytic, fatigue-sensitive (type 2) fibers, differential muscle fiber typing was carried out on the mid-belly of the tibialis anterior. The resulting staining patterns were analyzed to determine the relative number of type I and type II fibers present. In addition to fiber typing, fiber diameters were recorded during the histological analysis.

Animals were given intraperitoneal injections of calcein 48 and 24 hours before euthanasia. Calcein is a fluorescent dye that incorporates into growing bone and can be detected by epi-illumination microscopy. After euthanasia, proximal and distal tibiae were longitudinally sectioned, and the mid-planes of the growth plates were examined. The distance between the leading edge of calcein fluorescence for each injection was measured and tabulated and compared by $t$ test.

\section{Results}

Results show a steady increase in the force (Figure 2) as the leg is lengthened. The peak forces are small in the early part of lengthening then appear to increase magnitude as the lengthening progresses. The force then relaxes back to the pre-lengthened level. The gaps in the force readings in rabbit 1 are due to occasional short circuit in the wires, and on two occasions the large gaps in data are because the rabbit chewed through the wires. The wires were then repaired and the data collection resumed. This did not interrupt the lengthening protocol. For rabbit 2, the gap is solely due to chewing of the wires (Figure3). In both rabbits, the overall distraction force seems to plateau as the lengthening progresses. Figure 4 shows radiographs of rabbit 1 . The distraction gap can be clearly seen as lengthening proceeds.

Figure 5 shows that the peak force rose up to twice the resting force and exponentially decreased after each lengthening. Most of the force relaxation occurred within the first two hours after distraction. The lengthenings were performed in the mornings and evenings of each day. From the morning to evening the interval was 8 to 9 hours and from the evening to the next morning the interval was 15 to 16 hours. As can be seen in Figure 5, the peak force after the evening lengthening was consistently higher than the peak force after the morning lengthening. This seems to suggest that the longer the period between lengthening, the shorter the peak force. This may be interpreted as allowing enough time for the soft tissue to recover some of the tension created due to the lengthening.

Growth plate injury has been described in limb lengthening as arising from the forces generated in the distraction zone. We assessed bone growth in the proximal and distal tibiae. The results (Table 1) suggest that lengthening resulted in a significant reduction in bone growth in the distal tibial physis. The slower growth rate distally may be due to the smaller cross-sectional area in the distal tibia, resulting in a higher pressure exerted on that growth plate due to lengthening. In addition, the proximal tibial growth plate appeared morphologically similar in both limbs (Figure 6A \& B), but the distal growth plate of the lengthened limb appeared disorganized and lacked the characteristic columnar organization seen in the unlengthened tibia (Figure 6). These histologic findings are consistent with the bone growth determinations.

\begin{tabular}{|l|l|l|l|l|}
\hline & Right Proximal & Left Proximal & Right Distal & Left Distal \\
\hline Mean growth & 0.233 & 0.200 & 0.183 & 0.092 \\
\hline $\begin{array}{l}\text { Standard } \\
\text { deviation }\end{array}$ & 0.029 & 0.005 & 0.058 & 0.014 \\
\hline $\begin{array}{l}P \text { value } \\
(1 \text { tailed })\end{array}$ & & 0.092 & & $\mathbf{0 . 0 4 6}$ \\
\hline
\end{tabular}

Table 1: Average bone growth $(\mathrm{mm} /$ day) in rabbits after limb lengthening

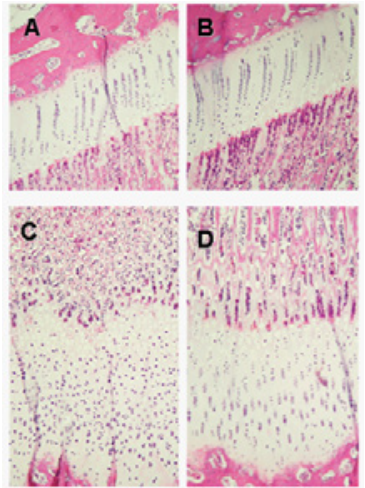

Figure 6: Comparison of growth plates from operated (left) and non-operated (right) limbs after limb lengthening in rabbits. (A) and (B) show proximal tibial growth plates stained with hematoxylin and eosin. Both limbs exhibited a distinctive columnar appearance in the proliferating and hypertrophic zones. (C) and (D) show distal tibial growth plates stained with hematoxylin and eosin. The control limb exhibits a distinctive columnar appearance in the proliferating and hypertrophic zones. The operated limb from the same animal exhibits a distorted appearance consistent with mechanical disruption.

\begin{tabular}{|l|l|l|l|}
\hline & Type I Fibers & Type II Fibers & Total \\
\hline Left/operated & 100 & 574 & 674 \\
\hline Right/control & 36 & 414 & 450 \\
\hline Total & 136 & 988 & 1124 \\
\hline
\end{tabular}

Table 2: Chi square table $\left(X^{2}=11.859\right.$; Significance $\left.<0.001\right)$

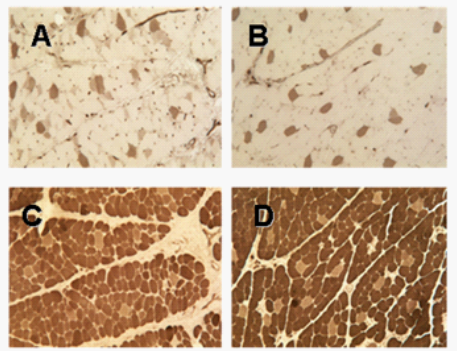

Figure 7: Comparison of muscle fiber types from operated (left) and nonoperated (right) tibialis anterior muscles. (A) and (B) show ATPase staining patterns prepared at $\mathrm{pH} 4.35$, which results in a darker appearance for type I fibers; (C) and (D) show ATPase stains of the same regions prepared at $\mathrm{pH} 10.2$, which results in a lighter appearance for type I fibers. Images like these were analyzed by the Histotechnology Core Facility to provide the data presented in Tables 2 and 3 . In the A, B and C, D image pairs, changes in the fiber-type distribution are ev.

Fixed-rate lengthening of tibiae in a rabbit model resulted in a change in muscle fiber-type distribution in the tibialis anterior. The results are summarized in Table 2 . The results indicate a statistically significant shift in the predominance of type I fibers from $8 \%$ of the total to $15 \%$ of the total fibers in the tibialis anterior samples (Figure 7). The distribution of fiber types is characteristic of muscle type and function, and rabbit tibialis anterior muscle sections typically contain a low proportion of type I fibers consistent with their role in rabbit locomotion [20]. An altered distribution of fibers is indicative of changes in muscle function or motor unit innervation, or both Although not quantified, there was also evidence of an intermediate muscle fiber type in the sections stained at low $\mathrm{pH}$ (ie, type IIa fibers). These intermediate fibers have moderate fatigue resistance, and their appearance in the operated leg is consistent with the increasing force on the muscle. The change in fiber type seen in these experiments is 


\begin{tabular}{|l|l|l|l|l|}
\hline & $\begin{array}{l}\text { Type I } \\
\text { Left (Op) } \\
\text { Side }\end{array}$ & $\begin{array}{l}\text { Type I } \\
\text { Right (Non- } \\
\text { Op) Side }\end{array}$ & $\begin{array}{l}\text { Type II } \\
\text { Left (Op) } \\
\text { Side }\end{array}$ & $\begin{array}{l}\text { Type II } \\
\text { Right (Non- } \\
\text { Op) Side }\end{array}$ \\
\hline $\begin{array}{l}\text { Mean relative } \\
\text { diameter }\end{array}$ & 3.58 & 4.64 & 2.30 & 3.57 \\
\hline $\begin{array}{l}\text { Mean diameter } \\
\text { rank }\end{array}$ & 61.95 & 86.69 & 378.52 & 655.31 \\
\hline $\begin{array}{l}\text { Mann Whitney } \\
\text { U-score }\end{array}$ & 1145 & & 55243 \\
\hline $\begin{array}{l}\text { Significance } \\
\text { (2 tailed) }\end{array}$ & & $\mathbf{0 . 0 0 1}$ & & $<0.001$ \\
\hline
\end{tabular}

Table 3: Fiber diameter analysis

consistent with a change in muscle function due to the load exerted by the distractor and suggests that fixed-rate limb-lengthening of a juvenile animal results in a significant alteration of fiber types similar to that seen in endurance training [21-23].

Fixed-rate lengthening of tibiae in a rabbit model resulted in a decrease in muscle fiber diameter in the tibialis anterior. Comparison of these diameters by fiber type, shown in Table 3, indicated that there was a statistically significant decrease in the diameter of both type I and type II fibers in the operated leg. These results indicate that lengthening resulted in apparent muscle "atrophy" consistent with disuse, and they support the conclusion that fixed-rate limb lengthening can result in aberrations in the associated muscle.

\section{Conclusions}

This study highlights the relationship between distraction force and muscle fiber physiology during limb lengthening. The distraction force spikes right after lengthening and then exhibits a characteristic decay over time until the next lengthening, which is similar to findings from other studies [4,9]. This decay is attributed to muscle tissue adaptation to stretch. Evidence suggests that the shorter the interval between lengthening, the higher the peak forces right after lengthening, indicating that the muscle still retains a stiffer characteristic early on in the recovery phase. As has been shown by others [16,23], because of the accumulated stresses and despite the small number of animals, there was a trend seen by a decrease in endogenous bone growth at the distal growth plate and change in muscle fiber-type distribution and fiber diameter in the tibialis anterior muscle.

\section{Acknowledgement}

Funding was provided by Nemours Biomedical Research. There are no conflicts of interest.

\section{References}

1. Ohnishi I, Kurokawa T, Horinaka S, Murashima R (1992) Measurement of tensile force during auto-continuous lengthening. Seikei Saigaigeka 35: 23-28.

2. Gardner TN, Evans M, Simpson AH, Kyberd PJ, Kenwright J (1997) A method of examining the magnitude and origin of "soft" and "hard" tissue forces resisting limb lengthening. Med Eng Phys 19: 405-411.

3. Simpson AH, Cunningham JL, Kenwright J (1996) The forces which develop in the tissues during leg lengthening. A clinical study. J Bone Joint Surg $\mathrm{Br} 78$ : 979-983.

4. Aarnes GT, Steen $H$, Kristiansen LP, Ludvigsen P, Reikerås $O$ (2002) Tissue response during monofocal and bifocal leg lengthening in patients. J Orthop Res 20: 137-141.

5. White SH, Kenwright J (1990) The timing of distraction of an osteotomy. J Bone Joint Surg Br 72: 356-361.

6. Aronson J, Harp JH (1994) Mechanical forces as predictors of healing during

tibial lengthening by distraction osteogenesis. Clin Orthop Relat Res 301: 7379.

7. Leong JC, Ma RY, Clark JA, Cornish LS, Yau AC (1979) Viscoelastic behavior of tissue in leg lengthening by distraction. Clin Orthop Relat Res 139: 102-109.

8. Wolfson N, Hearn TC, Thomason JJ, Armstrong PF (1990) Force and stiffness changes during Ilizarov leg lengthening. Clin Orthop Relat Res 250: 58-60.

9. Younger AS, Mackenzie WG, Morrison JB (1994) Femoral forces during limb lengthening in children. Clin Orthop Relat Res 301: 55-63.

10. Verkerke GJ, Schraffordt Koops H, Veth RP, Nielsen HK, van den Kroonenberg $\mathrm{HH}$, et al. (1989) Design of a load cell for the Wagner distractor. Proc Inst Mech Eng $\mathrm{H}$ 203: 91-96.

11. Pennecot GF, Herman S, Pouliquen JC (1983) Effects of progressive lengthening on the growth cartilage. Value of measurement of the torque. Rev Chir Orthop Reparatrice Appar Mot 69: 623-627.

12. Paley D, Fleming B, Catagni M, Kristiansen T, Pope M (1990) Mechanical evaluation of external fixators used in limb lengthening. Clin Orthop Relat Res 250: 50-57.

13. Kawamura B, Hosono S, Takahashi T, Yano T, Kobayashi Y, et al. (1968) Limb lengthening by means of subcutaneous osteotomy. Experimental and clinical studies. J Bone Joint Surg Am 50: 851-878.

14. Holly RG, Barnett JG, Ashmore CR, Taylor RG, Molé PA (1980) Stretch-induced growth in chicken wing muscles: a new model of stretch hypertrophy. Am J Physiol 238: C62-C71.

15. Shen XC, Aronson J (1993) Changes in biomechanical properties of muscle following tibial lengthening in rat. Proc 33rd Ann Meet Orthop Res Soc, San Francisco: 379.

16. Lee DY, Chung CY, Choi IH (1993) Longitudinal growth of the rabbit tibia after callotasis. J Bone Joint Surg Br 75: 898-903.

17. Simpson AH, Williams PE, Kyberd P, Goldspink G, Kenwright J (1995) The response of muscle to leg lengthening. J Bone Joint Surg $\mathrm{Br} 77$ : 630-636.

18. Simpson AH, Williams PE, Kyberd P, Goldspink G, Kenwright J (1991) The response of muscle to different rates of distraction. J Bone Joint Surg Br Suppl II: $189-190$.

19. Williams PE, Simpson AH, Kyberd P, Kenwright J, Goldspink G (1994) Changes in muscle compliance following limb distraction in the New Zealand white rabbit. Proc Anat Soc of Great Britain and Ireland: 189.

20. Lexell J, Jarvis JC, Currie J, Downham DY, Salmons S (1994) Fibre type composition of rabbit tibialis anterior and extensor digitorum longus muscles. J Anat 185: 95-101.

21. Wang YX, Zhang CL, Yu RT, Cho HK, Nelson MC, et al. (2004) Regulation of muscle fiber type and running endurance by PPARdelta. PLoS Biol 2: e294.

22. Rasbach KA, Gupta RK, Ruas JL, Wu J, Naseri E, et al. (2010) PGC-1alpha regulates a HIF2alpha-dependent switch in skeletal muscle fiber types. Proc Natl Acad Sci U S A 107: 21866-21871.

23. Yamazaki $\mathrm{H}$, Abe M, Kanbara K (2003) Changes of fiber type ratio and diameter in rabbit skeletal muscle during limb lengthening. J Orthop Sci 8: 75-78. 